\title{
APRENDIZAGEM DA DOCÊNCIA EM ESPAÇOS INSTITUCIONAIS: É POSSÍVEL FAZER AVANÇAR O CAMPO DA FORMAÇÃO DE PROFESSORES?
}

\author{
Maria Isabel da Cunha* \\ Recebido: 9 jun. 2014 \\ Aprovado: 31 jul. 2014
}

*Programa de Pós-Graduação em Educação da Universidade do Vale do Rio dos Sinos. São Leopoldo, RS, Brasil. E-mail: cunhami@uol.com.br

Resumo: A formação de professores tem sido um tema universalmente recorrente de estudos e reflexões. Talvez sejam dos temas mais abordados nas pesquisas do campo das ciências da educação. Constitui-se numa possibilidade inesgotável e sempre revisitada, dado que acompanha as visões e transformações sociais, culturais e econômicas da sociedade. Como a docência se caracteriza como uma profissão aninhada socialmente e atingida por valores políticos e culturais, se produz na dependência das compreensões que orientam os projetos educativos contextualizados. Há algum tempo, dada a fragilidade dos formatos tradicionais, caracterizados pela perspectiva exógena, a formação de professores vem reivindicando sua volta para o seio da profissão, valorizando a relação educação e trabalho e a potencialização da experiência dos sujeitos na sua própria formação, característica básica da aprendizagem dos adultos. Não mais vista apenas como um processo individual, movimentos e proposições se instalam assumindo a base do trabalho como espaço/lugar da formação. Ou seja, reivindicam a perspectiva das organizações aprendentes. O sujeito aprende quando se insere em espaços laborais que assumem para si essa condição. Essa é a posição defendida nesse ensaio afirmando que a formação de adultos se valoriza quando as modalidades nessa direção favorecem a capacidade dos atores, nas organizações, de produzirem seus próprios conhecimentos e esse é o caso dos professores.

Palavras-chave: Formação continuada de professores. Desenvolvimento profissional docente. Instituições aprendentes. Educação e trabalho.

\section{LEARNING TEACHING IN INSTITUTIONAL SPACES: \\ IS IT POSSIBLE TO MAKE ADVANCE THE TEACHER EDUCATION FIELD?}

Abstract: The training of teachers has been, universally, a recurring theme of study and reflection. Perhaps the most discussed topics in the research field of educational sciences. It constitutes an inexhaustible possibility and often revisited, given that accompanies the visions and social changes, cultural and economic in society. As teaching is characterized as a socially nested profession and affected by political and cultural values, is produced in dependence on understandings that guide contextual educational projects. For some time, given the weakness of traditional formats, characterized by exogenous perspective, teacher education has been demanding his return to the bosom of the profession, valuing the relationship education and work and the potentiation the experience of the subjects in their own training, basic characteristic of adult learning. No longer seen only as an individual process, movements and propositions are established assuming the basis of the work as a space / place of training. In other words, claim the prospect of learning organizations. The subject learns when inserting in work spaces that assume to themselves this condition. This is the position advocated in this essay affirming that adult education is valued when the modalities into this direction favor the capacity of actors in organizations, to produce their own knowledge and that is the case of teachers.

Key words: Continuing education of teachers. Teacher professional development. Learners institutions. education and work. 
São recorrentes e inúmeros os estudos sobre a formação de professores na contemporaneidade. No campo das ciências da educação, talvez seja este um dos temas mais recorrentes. Há reflexões em relação à natureza do trabalho docente, à perspectiva histórica que marcou a profissão de professor, às correntes teóricas que indicam características dos professores e dos seus saberes e das práticas bem sucedidas. Também há estudos de cunho sociológico, que enfocam a relação educação e trabalho e, nela, analisam o magistério no contexto das profissões. O fenômeno vem sendo estudado com ênfase, também, na perspectiva de gênero e na divisão do trabalho nas sociedades capitalistas. Os níveis de ensino se constituem, ainda, numa categoria que usualmente reúne investigações sobre a docência. Inclui as características e saberes daqueles que atuam, quer na educação infantil, quer na educação básica, ou na educação média, profissional ou superior. Atualmente já há investigações sobre os saberes dos professores que orientam dissertações e teses, num espaço próprio da pós-graduação, assim como os que se dedicam à educação à distância, entre outras modalidades. Essas produções indicam que há saberes gerais que definem a profissão, mas há outros que são produzidos em função das características dos públicos com quem interagem os professores. Além desses, a literatura tem sido pródiga em explicitar a condição contextual dessa formação e como os estruturantes locais interferem nos desejados processos formativos, num determinado tempo histórico.

Os conhecimentos da psicologia do desenvolvimento e da aprendizagem foram fortes referentes dos saberes dos docentes e de sua formação, definidos pela forma de como aprendem seus estudantes. Essa perspectiva, no Brasil, teve importante impacto desde o movimento escolanovista até os anos oitenta do século XX quando, por força da abertura democrática do país, os estudos de cunho sócio-filosófico assumiram um papel predominante. Mesmo assim, não há proposta de formação inicial de professores que não inclua a base da psicologia da educação. A ela se somaram outros tantos referentes, especialmente sociológicos, políticos e didáticos, na medida em que foi sendo assumida a condição da docência como uma profissão complexa.

Esta complexidade é reconhecida por suas características multifacetadas e pela multiplicidade de saberes que estão em jogo na sua formação, que exige uma dimensão de totalidade, distanciando-se da lógica da especialidade, tão cara a muitas outras profissões, na organização taylorista do mundo do trabalho. "Mesmo que seja factível a dedicação a um determinado campo de conhecimento, o exercício da docência exige múltiplos saberes que precisam ser apropriados e compreendidos em suas relações" (CUNHA, 2005, p. 41). 
Foram as chamadas teorias críticas, em forte expansão no mundo ocidental que, desde o final dos anos setenta, interferiram nas percepções dominantes da formação de professores realizada no espaço acadêmico e escolar que, até então, obedeciam às compreensões advindas da racionalidade técnica. Estas teorias, incorporando referenciais que relacionavam o conhecimento com sua forma de produção, foram responsáveis por uma significativa ruptura nos rumos da prática educativa. A sociologia constituiu-se num importante suporte para entender as relações de poder estabelecidas entre a educação e a sociedade, tornando a dimensão política do ato educativo um destacado estruturante de análise do contexto social.

O reconhecimento da educação como uma produção histórica e socialmente produzida estabeleceu-se como um pressuposto necessário ao entendimento da docência. Estudá-la pressupunha tomar o professor na sua condição concreta de vida, marcada por uma trajetória cultural e contextual. Não mais se admitia propor modelos universais e generalizáveis para a formação de professores, pois, apesar da identificação de componentes comuns presentes na base da profissão docente, as circunstâncias de sua produção se configurariam singularmente.

Como decorrência dessa compreensão, identificou-se uma inversão na lógica investigativa. Não mais se partia das matrizes e explicações teóricas para confirmá-las na prática. Ao contrário, tomava-se o real e o cotidiano como objeto aberto de estudo e procurava-se, a partir da apreensão da prática, encontrar explicações teóricas. Por exemplo, não se definia, a priori, quais os conhecimentos e saberes necessários ao professor com uma base rígida alicerçada no dever ser e no dever fazer. Ao contrário, ia-se ao campo entender como os professores de fato atuavam e a que saberes recorriam para enfrentar os desafios de sua profissão (CUNHA, 2004). Instalou-se a busca de uma genealogia, não como fim em si mesmo, mas como ponto principal de referência para fazer avançar o conhecimento e construir teorias que pudessem ajudar a explicação dos fenômenos. Esta perspectiva distanciou-se das grandes generalizações porque procurou valorizar tanto as regularidades como as especificidades das construções pedagógicas cotidianas. A cotidianidade assumiu uma importância significativa na compreensão do mundo e os estudos de Heller (1985), no campo da filosofia, foram uma preciosa ajuda para a construção da pesquisa e da reflexão sistematizada.

Esse arcabouço histórico conceitual do entendimento da docência e da mudança paradigmática, que vem afetando a concepção de conhecimento e incluindo novas racionalidades, tem tido importante influência no campo da 
formação de professores, fragilizando a compreensão de que o conhecimento profissional, entendido na perspectiva da racionalidade técnica, seja base da docência. Schön (1992) apontou esta inadequação, indicando três razões.

A primeira é de que, quando se assume que o conhecimento profissional possa ser produzido fora da situação em que deve ser aplicado, ignora-se que o conhecimento sempre deve "estar inserido em um contexto socialmente estruturado, compartilhado pela comunidade dos praticantes e exercido através dos meios institucionais concretos da profissão" (p. 95).

A segunda razão, apontada pelo autor, sustenta-se na impossibilidade concreta, reafirmada pelos professores, de uma aplicação linear da teoria à prática. Os professores, em geral, atuam desde a base do conhecimento que constroem na prática cotidiana da docência. Trata-se de um conhecimento prático herdado que envolve um conjunto de valores, opções e referências que dão sentido às suas ações concretas.

A terceira razão refere-se ao fato de que, os problemas da vida real são únicos e contextualizados e, portanto, não podem ser resolvidos apenas mediante o uso de técnicas derivadas da investigação teórica. Schön aponta a necessidade de uma competência artística para que o professor encaminhe adequadamente a sua prática, apelando para outras racionalidades que não apenas as que se baseiam na razão cognitiva-instrumental.

A compreensão da educação como produto das condições sociais e históricas recuperou o fundamental papel político que a sustenta. Paulo Freire deu significativas contribuições neste sentido. Diz ele que "não há educação fora das sociedades humanas e não há homem no vazio" (1977, p. 35). Afirma, ainda, que, por essa razão, "educação é diálogo, na medida em que não é transferência de saber, mas um encontro de sujeitos interlocutores que buscam a significação dos significados" (1982, p. 69).

A reflexão sobre a formação de professores é subsidiária das compreensões políticas da educação. As posturas filosóficas e epistemológicas que sustentam estas compreensões têm relação direta com as propostas de formação. Esta referência tem favorecido os estudos que recuperam os processos formativos na sua constituição histórica, ligando-os a tendências paradigmáticas que revelam em seus perfis.

Entretanto nas últimas décadas, as relações entre educação e trabalho vão se explicitando cada vez com mais força na sociedade contemporânea, onde a lógica do mercado tem tido forte influência. Progressivamente a educação vem sendo potencializada como um capital cultural que tem alto poder definidor da posição que os indivíduos ocupam na estrutura social. A chamada "sociedade 
da informação" potencializa essa condição e, ainda, "há o pressuposto de que ela pode dirigir os indivíduos assegurando uma requalificação profissional e/ ou pessoal que se admite ser imprescindível ao bom funcionamento dos espaços sociais e/ou profissionais onde eles se inserem" (CORREIA, 1997, p. 22).

Essa perspectiva ainda revela a percepção de que as situações de formação são exteriores ao exercício do trabalho, fundamentalmente ligadas a um constructo laboral generalizador, baseado em competências pré-definidas. Ou seja, a expectativa é de que "a formação tenha efeitos a posteriori, contribuindo apenas para o restabelecimento do equilíbrio do sistema, assegurando a adaptação técnica e, eventualmente, a adaptação psicológica dos indivíduos ao novo contexto" (CORREIA, 1997, p. 23).

Este postulado encontra guarida na cultura escolarizada e acadêmica, com certa facilidade. A compreensão da formação inicial, como pressuposto da profissionalização dos indivíduos, se constitui quase num monopólio da universidade e dos sistemas escolarizados. Ela procura garantir certa coerência universal com o que a sociedade projeta para cada carreira e, no contexto da divisão social do trabalho, define espaços monopolizados para seu exercício. Representa, sob o argumento de garantia aos interesses da sociedade, um controle sobre a distribuição do conhecimento especializado, valorizando o capital de quem os detém.

No caso da formação de professores, no Brasil, os Cursos de Licenciatura são responsáveis pela docência na educação básica e a pós-graduação stricto sensu vem sendo progressivamente responsabilizada pela formação para a educação superior.

A formação inicial de professores pode ser compreendida como os processos institucionais de formação da profissão que geram a licença para seu exercício e o seu reconhecimento legal e publico. Entretanto, tem sido enfática a compreensão de que a formação inicial representa uma etapa na trajetória formativa e, mesmo sendo importante, não é mais suficiente para que o desempenho que o campo profissional exige. Esse sentimento se acirrou na dita sociedade do conhecimento, quando a celeridade da sua produção e das formas de sua distribuição aumentou significativamente. Ao mesmo tempo a flexibilização do emprego, relacionada à volatibilidade do mercado, criou a sensação de incompletude permanente e o imperativo da constante formação.

Por outro lado, não raras vezes, os diplomas não mais garantem o direcionamento para os ofícios, quer pelos limites das ofertas de trabalho, quer pela cultura da mobilidade no emprego muito mais evidente para as gerações que atuam no cenário contemporâneo. Dubar afirma que essa condição afeta 
as identidades profissionais, reivindicando uma identidade "fora do trabalho" partilhando formações em redes (1997, p. 47), mais plurais e menos identitárias, ou seja, compreendidas como as formas de viver o trabalho. Nelas, não há constâncias universais, pois variam no espaço e no tempo e dependem do contexto histórico. Não decorrem de nenhuma teoria e precisam, segundo o autor, ser reconstruídas indutivamente, recorrendo às formas discursivas sobre o trabalho e a formação.

Esses pressupostos põem em questão as formas tradicionais de formação continuada de professores que, em geral, ainda se instituem expondo os docentes a reflexões teóricas produzidas por outros, seja em forma de leituras ou de audição de palestras e conferências.

Ainda que essas possam ser, em determinadas circunstâncias, mobilizadoras de reflexões, se não forem inseridas numa perspectiva de trajetória de formação, a partir da ação, pouco contribuirão para o desenvolvimento profissional dos docentes. A educação continuada de professores refere-se a iniciativas instituídas no período que acompanha o tempo profissional dos professores. Pode ter formatos e duração diferenciados, assumindo a perspectiva da formação como processo e responsabilizando as instituições como atores principais do seu patrocínio (CUNHA, 2013). Tanto mais aproximam as condições de formação com as de trabalho, mais poderão ter sentido e significado nos contextos em que atua.

Malglaive (1997) tem chamado de saberes da ação aqueles ligados aos desafios e soluções para as práticas, relacionados aos procedimentos elaborados. Mas adverte que esses são saberes difíceis, "porque não há livros sobre os saberes da ação" (p. 56), referindo-se a inutilidade de manuais prescritivos para compreender realidades que são sempre únicas e contextualizadas nos processos de aprender uma profissão.

O autor defende a necessidade de se quebrar a compreensão de que a educação continuada significa um prolongamento da formação inicial, portanto com forte componente da tradição acadêmica, onde os saberes contextuais da prática são raramente incluídos. Esta perspectiva tem se mostrado inadequada, pois há grande dificuldade de se transferir as aquisições formativas de um contexto para outro. Por essa razão, no caso dos professores, cada vez mais se preconiza uma formação que regresse aos espaços de trabalho e os tenha como referente das ações formativas (NÓVOA, 1999).

Professores são adultos que aprendem e essa condição apresenta características próprias. Valorizam, principalmente, as modalidades de formação e as suas capacidades enquanto protagonistas das suas trajetórias nos seus contex- 
tos profissionais. Lembra Barroso (1997, p. 74), que "trata-se de criar condições em que se possa estabelecer uma integração entre o lugar de aprender e o lugar de fazer, bem como é preciso que sejam criadas condições para que se produza outra relação entre saber e poder". Certamente essa perspectiva envolve outras condições, relacionadas com a gestão participativa e o respeito mútuo entre os envolvidos. Como desejável, é preciso que haja lideranças que estimulem as mudanças necessárias e o processo de desenvolvimento dos docentes.

\section{A FORMAÇÃO DE PROFESSORES NUMA INSTITUIÇÃO APRENDENTE}

Defendemos, então, ao nos identificarmos com os autores que ajudam as reflexões aqui apresentadas, que a formação continuada de professores precisa estar aninhada numa instituição aprendente. Nesse exercício, ela poderá valorizar a experiência dos seus professores e criar condições para que eles participem da tomada de decisões.

Mas Barroso (1997, p. 75) alerta que, para tal, é preciso evitar duas perspectivas: a) a visão gerencialista, que situa a formação como componente da técnica organizacional; b) a perspectiva voluntarista, que delega à boa vontade de cada um a iniciativa de se engajar nos processos de mudança e desenvolvimento profissional.

A primeira tem na estratégia sua centralidade, pouco levando em conta os sujeitos e contextos; a segunda corre o risco de apostar no espontaneismo e na perspectiva individual dos sujeitos, desconsiderando os objetivos do processo educativo que orienta a formação. Essa, quando assume o trabalho como espaço de execução, precisa ter direção, assumindo os valores e intencionalidades que justificam a instituição como referente. Exige que os docentes tenham um conhecimento significativo sobre ela, sejam capazes de realizar diagnósticos que evidenciem seus desafios, mobilizem suas experiências e suas potencialidades.

Essas perspectivas vêm ligadas ao campo das aprendizagens organizacionais. Afirmam Argyris e Schön $(1978$, p. 3) que "os indivíduos aprendem como parte de suas atividades diárias, especialmente quando entram em interação com os outros e com o meio exterior. Os grupos aprendem quando os membros cooperam para atingir objetivos comuns. O sistema aprende, ao obter retroalimentação do ambiente e antecipa mudanças posteriores".

Parece ser esta uma possibilidade importante para se refletir sobre a formação de professores. Não há mais condições de percebê-la como uma respon- 
sabilidade individual e um processo solitário. As aprendizagens acontecem quando há uma cultura institucional que as estimulam e as valorizam. Portanto, parece que a hora é de provocar as instituições para se constituírem no principal dispositivo de formação de seus professores. Para tal, além da socialização de seus princípios e práticas, é preciso confiança e a compreensão do professor como um intelectual, um adulto que aprende pelo que faz e reflete.

Para tal, Bolivar (1997, p. 85) sugere dois procedimentos importantes: “a) Aprender pela experiência acumulada, ou o exercício da memória coletiva institucional; b) Aprender com os projetos postos em prática". O equilíbrio entre os dois favorece a estabilidade da história coletiva da instituição e, ao mesmo tempo, possibilita a renovação e a aprendizagem pela experiência concreta.

Temos defendido que a valorização das experiências dos professores com seus estudantes se constitui no campo preferencial de formação e de teorização das práticas pedagógicas na educação escolarizada. Sua exploração se estabelece como referência da reflexão, analisando avanços, peculiaridades e desafios.

A socialização dessas experiências pressupõe valorizar o trabalho compartilhado, interromper uma tradição cultural de que a responsabilidade pela docência é individual e autônoma. Ao contrário, exige um esforço de construir comunidades docentes de aprendizagem, onde o que um professor vive pode contribuir com outros.

Nesse contexto, a valorização das experiências positivas, entendidas como aquelas em que o professor reconhece avanços nos processos de ensinar e que os estudantes percebem como qualificadoras das suas aprendizagens, são as mais potencializadoras para os processos de formação ligados ao mundo do trabalho. Longe da intenção de construir modelos facilmente repetíveis e ingenuamente transferíveis, socializar as chamadas "boas práticas" tem como objetivo a construção de reflexões sobre os saberes em movimento e a disposição de aprender com a experiência dos demais docentes.

No caso da docência universitária, temos defendido que é necessário aproveitar a cultura da pesquisa para pensar o ensino e a formação que esta ação demanda. Como os docentes da educação superior tem sua formação alicerçada nos saberes investigativos, é importante estimulá-los a desenvolver os saberes do ensino com os mesmos pressupostos.

Há de se perguntar, porém, porque a investigação sobre o ensino tem sido pouco valorizada no contexto da docência, em todos os niveis, mesmo na universidade onde a pesquisa é parte constituinte do saber docente? 
Certamente uma das razões está ligada ao baixo estatuto epistemológico do conhecimento pedagógico que, para a maioria dos professores, está ligado ao senso comum, a aprendizagens somente empíricas. A profissão docente, entre tantas outras, talvez seja a que com mais intensidade se instala no imaginário social. Todos sabem o que faz um professor e como esse profissional atua no cotidiano de seu trabalho. Então, por reprodução dessas práticas, qualquer pessoa crê que pode exercer a docência.

Outra razão está ligada ao campo da subjetividade. A docência é uma profissão que atua no campo das relações humanas e envolve saberes que se distanciam da racionalidade técnica, ainda tão presente na base do conhecimento científico. Muitas vezes essa condição, inegavelmente constituinte da profissão de professor, assume uma dimensão preponderante, onde parece que a ciência não exerce um papel reconhecido.

Essas são duas possibilidades explicativas que assentam a docência no saber fazer. Entretanto se afasta da compreensão que Tardif (2002) dá para o termo saber, quando se refere que um saber se institui quando, além de saber fazer, o docente sabe justificar porque faz. E essa justificativa, na perspectiva profissional, precisa extrapolar os argumentos do senso comum e apoiar-se em conhecimentos produzidos pelas ciências da educação. Para tal, a pesquisa é imprescindível e a profissionalidade dos docentes se fortaleceria na medida em que seus saberes profissionais fossem reconhecidos e impactassem as suas práticas.

Entretanto essa é uma análise recente e pouco tem tido consequências sobre os processos de formação dos professores. No caso da educação superior o fenômeno é mais evidente, pois, ainda que o percurso formativo dos docentes se alicerce nos saberes da pesquisa, não há iniciativas que assumam a docência como portadora de saberes profissionais. Ao contrário, se naturaliza que, para ensinar, basta o domínio do conhecimento específico das matérias acadêmicas e que a pesquisa sobre esse fazer tem quase nulo valor na arena acadêmica.

Dessa forma a universidade não aprende com o que faz, não potencializa a experiência relacionada com sua principal missão: o ensino e a formação das gerações que lhes são confiadas. Ou seja, não assume o papel de instituição aprendente e desperdiça a experiência, como denuncia Sousa Santos (2000). E, sendo ela a portadora da licença para formar professores nos demais graus de ensino, encontra muita dificuldade para expandir uma perspectiva diferente das práticas que vivencia.

Poder-se-ia, certamente, apontar outras razões para compreender porque a universidade desperdiça a sua condição de aprendente. Em boa escala está 
certa soberba em relação ao seu papel social. Colocar-se como aprendente significa reconhecer a incompletude, um "não saber" que não é comum nos espaços escolarizados. Historicamente, alicerçada na compreensão da ciência moderna, o conhecimento válido é aquele que não admite duvidas e incertezas. Mostrar essa face institucional, no imaginário preponderante, significa fragilidade e uma condição não desejada. Essa perspectiva vem, com maior ou menor intensidade, acompanhada de uma condição autoritária, que classifica saberes e dicotomiza o sujeito e a experiência. Estar em posição de aprendente exige uma mudança cultural, pois altera valores acadêmicos até então acarinhados. Envolve assumir a dúvida como valor e a incompletude dos esforços confrontados com os desafios cotidianos. Pressupõem a humildade, no sentido freiriano, onde é preciso assumir que "o diálogo como encontro dos homens para a tarefa comum do saber agir se rompe se seus polos (ou um deles) perdem a humildade" (FREIRE, 1970, p. 31).

Essa condição é desafiante para o professor que assume a representação de que a segurança e o domínio total da informação é que garante sua autoridade. A alteração dessa perspectiva exige maturidade e capacidade pedagógica que muitos docentes ainda não alcançaram. Torna-se mais desafiante, ainda, para os que principiam suas carreiras e que, em geral, não encontram a condição institucional de um espaço aprendente.

Por fim, mesmo sem esgotar o tema, cremos que, no caso da educação superior, a nebulosidade do conceito da indissociabilidade do ensino, pesquisa e extensão é mais uma razão para dificultar a compreensão de instituição aprendente, no que se refere ao ensino e à formação de professores.

Sendo um postulado universal, esse conceito tem orientado uma posição de unanimidade, sem questionamentos. Ramsden y Moser (1992, p. 273) argumentam que "há poucas crenças no mundo acadêmico que suscitam defesas tão apaixonadas como a opinião de que a docência e a investigação são atividades complementares e que mutuamente se beneficiem". Porém registram de forma enfática, que "poucas vezes um postulado dessa natureza tem sido objeto de estudos e pesquisas empíricas".

Em estudo anterior (CUNHA, 2012) exploramos, tendo como base universidades brasileiras, as representações sobre o conceito de indissociabilidade do ensino, pesquisa e extensão e a percepção de seu impacto nas práticas acadêmicas, em especial de docentes e estudantes. Os resultados reafirmaram as compreensões dos autores do Reino Unido, evidenciando, pelo menos, quatro entendimentos desse conceito e seu impacto no cotidiano universitário. O primeiro, denominamos de Visão epistemológica e as capacidades acadêmicas. 
Nele entende-se a indissociabilidade como "uma condição fundamental para o professor e o aluno, tendo em vista o desenvolvimento de sua capacidade de pensar e essa é uma condição intrínseca ao intelectual que se espera que eles sejam" (p. 33). Trata-se do incentivo aos processos cognitivos de suspeita das verdades consagradas e da capacidade de observação da realidade empírica. Constitui-se num modo de pensar e de proceder frente ao conhecimento.

A segunda perspectiva é a mais usual e centra na instituição o eixo dessa relação. Denominamos Visão institucional e de distribuição do conhecimento. Em geral não se responsabiliza todos os professores e estudantes pelo exercício das três tarefas, mas crê-se que todos devem se beneficiar dos produtos de cada uma, com acesso publico e universal (CUNHA, 2012, p. 33). Dilui-se a compreensão do significado de indissociabilidade, legitimando uma territorialização para cada uma das funções, inclusive na estrutura organizacional das IES.

A terceira visão conceituamos como Visão Metodológica nas formas de produzir o conhecimento, sustentada por aquele que "entendem a pesquisa como princípio metodológico. Nessa compreensão de indissociabilidade, o que está em pauta é uma concepção de aprendizagem como processo de construção do conhecimento" (p. 34).

A quarta dimensão foi explicitada como Visão política e de impacto social onde a indissociabilidade tem como premissa a esperança de superação das desigualdades sociais, pois envolveria a distribuição de bens culturais, expressando o papel da universidade na construção de uma sociedade mais justa e igualitária, aproximando-se da proposição de Sousa Santos (2010).

O exercício investigativo que possibilitou explicitar a exígua reflexão sobre o conceito de indissociabilidade presente no campo da educação superior favoreceu compreender as suas consequências. Inclui-se nessa condição, a contínua discussão sobre os indicadores de qualidade do ensino superior que estará na decorrência da compreensão adotada.

Uma instituição aprendente teria de manter em pauta a constante reflexão sobre seu papel e suas práticas e como significa o conceito de indissociabilidade que, no caso do Brasil, é preceito constitucional. Portanto anuncia inexoravelmente para um patamar de qualidade, baseado nesse pressuposto.

No caso do ensino, entender a indissociabilidade na Visão Metodológica nas formas de produzir o conhecimento envolve assumir a pesquisa como base dos processos didáticos que colocam o estudante frente ao conhecimento e exige do professor uma ação investigativa sobre o ensino que realiza. Quando potencializada essa condição se institui como espaço aprendente, dando à 
formação docente uma possibilidade de aprender com a experiência, devidamente teorizada.

De alguma forma, o ensino que faz da pesquisa seu pressuposto metodológico, atende, também, os pressupostos da Visão Epistemológica e das capacidades acadêmicas, pela compreensão de conhecimento que assume e pode chegar próximo à perspectiva da Visão política e de impacto social, pois a problematização da realidade exigida pela pesquisa tende a gerar o retorno do conhecimento para a base social.

$\mathrm{O}$ fato é que o silenciamento da reflexão sobre o preceito da indissociabilidade do ensino, pesquisa e extensão pode ser responsável pela dificuldade da universidade assumir a sua condição de aprendente.

Trazer esses três argumentos como empecilho para a tal, pode nos ajudar a avançar na sua superação. Reforçamos que o baixo estatuto epistemológico do conhecimento pedagógico, a condição da docência ser uma profissão fortemente ligada ao campo da subjetividade e a nebulosidade do conceito da indissociabilidade do ensino, pesquisa e extensão na comunidade acadêmica tem sido fatores que podem estar justificando a precariedade da formação docente na universidade.

Superar essa condição parece um imperativo frente aos desafios contemporâneos, onde os discursos da aprendizagem contínua são recorrentes. Torná-lo uma condição de desenvolvimento profissional que tenha significado para docentes e estudantes desafia a cultura acadêmica, as políticas educacionais e o campo das ciências pedagógicas. Esforços nesse sentido é que poderão anunciar cenários distintos para uma formação de professores que se alicerça em instituições aprendentes. Assim, pelo exemplo das práticas ensinaríamos as próximas gerações a se constituírem em eternos aprendizes, com preconizou Gonzaguinha (1981), como condição da vida e da felicidade. Os professores são adultos que aprendem e, em muitos casos são para eles que ensinam. Atuam em contextos sociais e institucionais prenhes de expectativas e regulações objetivas e simbólicas. Entender os significados que atribuem aos seus saberes se constitui na base da formação. 


\section{REFERÊNCIAS}

ARGYRIS, C.; SCHÖN, Donald. Organizational learning: a theory of action perspective. Reading/Mass: Addison-Wesley, 1978.

BARROSO, João. Formação, projecto e desenvolvimento organizacional. In: CANÁRIO, Rui (Org.). Formação e situações de trabalho. Porto: Porto Editora, 1997. p. 61-78.

BOLIVAR, Antonio. Escola como organização que aprende. In: CANÁRIO, Rui (Org.). Formação e situações de trabalho. Porto: Porto Editora, 1997. p. $79-100$.

CORREIA, José Alberto. Formação e trabalho: contributos para uma transformação dos modos de os pensar na sua articulação. In: CANÁRIO, Rui (Org.). Formação e situações de trabalho. Porto: Porto Editora, 1997. p. $13-42$.

CUNHA, Maria Isabel da. A docência como ação complexa: o papel da didática na formação de professores. In: ROMANOWSKI, Joana; MARTINS, Pura Lucia, JUNQUEIRA, Sérgio. Conhecimento local e universal: pesquisa, didática e ação docente. Curitiba: Editora Universitária Champagnat, 2004. v. 1.

CUNHA, Maria Isabel da. Impactos das políticas de avaliação externa na configuração da docência. In: (Org.). Formatos avaliativos e concepção de docência. São Paulo: Autores Associados, 2005. p. 49-68.

CUNHA, Maria Isabel da. (Org.). Qualidade da graduação: a relação entre ensino, pesquisa e extensão e o desenvolvimento profissional docente. Araraquara/SP: Junqueira\&Marins, 2012.

CUNHA, Maria Isabel da. O tema da formação de professores: trajetórias e tendências de formação do campo na pesquisa e na ação. Educação e Pesquisa, São Paulo, n. 3, p. 609-625, jul./set. 2013.

DUBAR, Claude. Formação, trabalho e identidades profissionais. In: CANÁRIO, Rui (Org.). Formação e situações de trabalho. Porto: Porto Editora, 1997. p. 43-52.

FREIRE, Paulo. Pedagogia do oprimido. Rio de Janeiro: Paz e Terra, 1970. 
FREIRE, Paulo. Ação cultural para a liberdade. Rio de Janeiro: Paz e Terra, 1977.

FREIRE, Paulo. Educação como prática da liberdade. Rio de Janeiro: Paz e Terra, 1982.

HELLER, Agnes. O cotidiano e a história. São Paulo: Paz e Terra, 1985. GONZAGUINHA. O que é o que é? 1981. 1 CD

MALGLAIVE, Gérard. Formação e saberes profissionais: entre a teoria e a prática. In: CANÁRIO, Rui (Org.). Formação e situações de trabalho. Porto: Porto Editora, 1997. p. 53-60.

NÓVOA, António. Os professores na virada do milênio: do excesso dos discursos à pobreza das práticas. Educação e Pesquisa, São Paulo, v. 25, n. 1, p. 11-20, jan./jun., 1999.

RAMSDEN, Paul; MOSER, Ingrid. Associations between research and teaching in Australian higher education. Higher Education, Sidney, v. 3, n. 3, p. 275-295, April, 1992.

SCHÖN, Donald. Formación de profesionales reflexivos. Barcelona: Piados Ibérica, 1992.

SOUSA SANTOS, Boaventura de. A crítica da razão indolente. Contra o desperdício da experiência. São Paulo: Cortez, 2000.

SOUSA SANTOS, Boaventura de. A universidade no século XXI: para uma reforma democrática e emancipatória da universidade. São Paulo: Cortez, 2010.

TARDIF, Maurice. Saberes docentes e formação profissional. São Paulo: Cortez, 2002. 